\title{
Reprodução de Meloidogyne incognita raça 1 e produtividade de cultivares de ervilha sob diferentes lâminas de água
}

\author{
João Maria Charchar(1), Waldir Aparecido Marouelli(1), Leonardo de Britto Giordano( ${ }^{(1)}$ \\ e Fernando Antônio Silva Aragão(1)
}

(1)Embrapa Hortaliças, Caixa Postal 218, CEP 70359-970, Brasília, DF. E-mail: charchar@cnph.embrapa.br

\begin{abstract}
Resumo - O objetivo deste trabalho foi avaliar o efeito de seis lâminas de água no fator de reprodução (FR) e no índice de galhas (IG) de Meloidogyne incognita raça 1 e na produtividade de oito cultivares de ervilha em condições de Cerrado, no Distrito Federal. O delineamento experimental foi em blocos ao acaso com parcelas subdivididas e quatro repetições. Os tratamentos constaram da combinação de oito cultivares (Triofin, Mikado, Marina, Viçosa, Maria, Luiza, Amélia e Kodama) e seis lâminas de água (156, 177, 239, 311, 395 e 479 mm). Não houve interação entre cultivares e lâminas de água para fator de repodução e índice de galhas do nematóide, mas houve para produtividade de grãos. As médias de FR e IG por cultivar nas seis lâminas não diferiram entre si, mostrando que as cultivares apresentaram o mesmo grau de suscetibilidade ao nematóide. As médias das oito cultivares por lâmina de água mostraram redução do fator de reprodução em 60\% sob lâminas de 156 e 177 mm, indicando que o nematóide não tolerou a condição de déficit hídrico do solo. As produtividades não diferiram nas lâminas de 239 a 395 mm, mas foram reduzidas em 12, 30 e 40\%, respectivamente, sob lâminas de 479, 177 e $156 \mathrm{~mm}$. As cultivares de ervilha alcançaram melhores produtividades sob lâminas de água entre 239 e $395 \mathrm{~mm}$.
\end{abstract}

Termos para indexação: Pisum sativum, irrigação, nematóide-de-galhas, tensão de água no solo.

\section{Reproduction of Meloidogyne incognita race 1 and yield of pea cultivars under different water depths}

\begin{abstract}
The objective of this work was to evaluate the effect of six water depths on the reproduction factor and gall index of Meloidogyne incognita race 1 as well as yield of eight pea cultivars in Cerrado conditions of the Federal District, Brazil. Treatments were replicated four times in a completely randomized block design and combined eight pea cultivars (Triofin, Mikado, Marina, Viçosa, Maria, Luiza, Amélia and Kodama) besides six water depths, 479, 395, 311, 239, 177 and $156 \mathrm{~mm}$. There was no interaction between cultivars and water depths for the nematode reproduction factor and gall index, but there was for yield. The means for reproductive factor and gall index per cultivar in the six water depths did not differ, showing that the cultivars presented the same degree of susceptibility. However, the general means of the eight cultivars for each water depth showed that the reproductive factor reduced by $60 \%$ in water depths of 156 and $177 \mathrm{~mm}$, indicating that the nematode did not tolerate water deficit. Cultivar yield did not differ, considering water depths of 239 to $395 \mathrm{~mm}$, but it reduced to 12 , 30 and $40 \%$, respectively, considering water depths of 479, 177 and $156 \mathrm{~mm}$. Pea cultivars reached the best yield under water depths of 239 to $395 \mathrm{~mm}$.
\end{abstract}

Index terms: Pisum sativum, irrigation, root-knot nematode, soil water retention.

\section{Introdução}

A ervilha (Pisum sativum L.) é uma das principais hortaliças leguminosas cultivadas no Brasil Central no período de inverno seco, com uma área plantada na região do Cerrado de aproximadamente 3.500 ha (FAO, 2004). A ervilha é hospedeira dos nematóides-de-galhas Meloidogyne spp., que causam danos consideráveis em condições de campo (Charchar, 1995; Santos \& Ferraz, 1995). As espécies M. incognita (Kofoid \& White)
Chitwood, 1949, M. javanica (Treub) Chitwood, 1949, M. arenaria (Neal) Chitwood, 1949 e M. hapla Chitwood, 1949, já foram encontradas associadas com cultivos da ervilha no Brasil. A espécie M. incognita e M. javanica são as mais comuns em ervilha (Charchar, 1995; Siddiqui et al., 1995; Zambolim et al., 1997; Sharma \& Fonseca, 2000), podendo ocorrer com freqüência em cultivos irrigados na região do Cerrado (Souza et al., 1998; Charchar, 1999). As espécies M. arenaria e M. hapla foram também encontradas em áreas restri- 
tas da região de Cerrado (Charchar, 1995), e M. hapla predomina em regiões de climas temperados (Howard et al., 1994; Charchar, 1999).

As espécies do gênero Meloidogyne atacam plantas de ervilha, provocando sintoma primário como galhas nas raízes. As galhas resultam da hiperplasia e hipertrofia dos tecidos radiculares que bloqueiam a absorção de água, causando a murcha de plantas nos horários mais quentes (Charchar, 1999). As galhas nas raízes bloqueiam também a absorção de nutrientes do solo, tornando as plantas raquíticas e amareladas, sintomas que se confudem com os de severa deficiência mineral da planta (Camacho et al., 1995; Charchar, 1999; Peña, 2000).

Plantas de ervilha infectadas, quando arrancadas, exibem raízes deformadas, com galhas coalescentes que apodrecem com facilidade. É comum a condição de tolerância em algumas cultivares, que mesmo mostrando inúmeras galhas no sistema radicular, apresentam aparência normal ou mesmo baixa redução em produtividade (Charchar, 1999; Santos, 2000).

O controle dos nematóides-de-galhas, em ervilha e outras culturas na região de Cerrado, é feito, preferencialmente, pelo uso da rotação de culturas com gramíneas (milho e sorgo) e plantas leguminosas (crotalárias, estilosantes e mucunas) que não são hospedeiras dos nematóides (Charchar, 1999; Sharma \& Fonseca, 2000; Charchar \& Aragão, 2003).

Os nematóides-de-galhas são extremamente dependentes das condições de clima, principalmente temperatura, umidade, aeração e composição química do solo (Charchar, 1999). No Cerrado, a ervilha é cultivada no período de inverno seco, com temperaturas do solo podendo variar de $15^{\circ} \mathrm{C}$ a $25^{\circ} \mathrm{C}$, sendo a irrigação uma prática indispensável. A irrigação é realizada por aspersão, e o pivô-central é o sistema mais utilizado (Giordano et al., 1997). A cultura requer adequado suprimento de água para o bom desenvolvimento e a produtividade de grãos (Marouelli et al., 1991; Aguiar Netto et al., 1995, 1997; Figuerêdo, 1999). Porém, o manejo inadequado da irrigação, seja pelo excesso ou falta de água, reduz significativamente a produtividade e a qualidade de grãos, além de favorecer a incidência de várias doenças (Marouelli et al., 1991; Charchar, 1999; Oliveira et al., 2000).

Nos cultivos tardios de ervilha, os nematóides-degalhas infectam mais gravemente a cultura sob irrigação, quando a temperatura do solo é mais elevada com variação de $18^{\circ} \mathrm{C}$ a $28^{\circ} \mathrm{C}$. Porém, nos cultivos de inverno seco no Cerrado, com temperaturas do solo entre $15^{\circ} \mathrm{C}$ e $25^{\circ} \mathrm{C}$, os nematóides ainda podem causar danos à cultura. $\mathrm{O}$ manejo da irrigação tem sido utilizado como alternativa para reduzir as populações de nematóides nos solos de cerrado cultivados com ervilha e outras culturas (Charchar, 1999).

O excesso de água pode induzir condição anaeróbica no solo (déficit de oxigênio), e a falta de água facilita a dessecação do solo (déficit hídrico), com efeitos na redução populacional de nematóides no solo (Charchar, 1995, 1999), além de reduzir a produtividade de grãos (Marouelli et al., 1991). Estes autores ainda relatam que o maior rendimento da ervilha nos Cerrados do Brasil Central é obtido quando as irrigações são realizadas a todo momento que a tensão de água no solo, avaliada a $50 \%$ da profundidade efetiva do sistema radicular, atingir $200 \mathrm{kPa}$. Portanto, a adoção do manejo da irrigação com uso racional da quantidade de água aplicada, resultando no decréscimo populacional dos nematóides-de-galhas sem perda significativa da produtividade de grãos, seria de grande importância para o sucesso de cultivo da ervilha nos Cerrados do Brasil Central.

O objetivo deste trabalho foi avaliar o efeito de seis lâminas de água no fator de reprodução e no índice de galhas de $M$. incognita raça 1 e na produtividade de grãos de oito cultivares de ervilha, em condições de Cerrado do Distrito Federal.

\section{Material e Métodos}

O experimento foi conduzido no campo experimental da Embrapa Hortaliças, Brasília, DF, em solo classificado como Latossolo Vermelho distrófico, fase cerrado, textura argilosa (11\% de areia; $19 \%$ de silte; $70 \%$ de argila) e $\mathrm{pH} 5,9$. A temperatura do solo a $20 \mathrm{~cm}$ de profundidade, medida com termômetro de haste, variou de $20,5^{\circ} \mathrm{C}$ a $24,5^{\circ} \mathrm{C}$ no período experimental. A retenção de água no solo (\%vol.), entre 0 e $40 \mathrm{~cm}$ de profundidade, no intervalo de tensão ( $\Psi \mathrm{m})$ de 5 a $1.500 \mathrm{kPa}$, foi ajustada à equação de Genuchten (1980), produzindo a seguinte relação:

$$
\theta\left(\Psi_{\mathrm{m}}\right)=23,0+14,8 /\left[1+\left(0,057 \times \Psi_{\mathrm{m}}\right)^{1,657}\right]^{0,397}
$$

$\mathrm{O}$ delineamento foi em blocos ao acaso, com parcelas subdivididas e quatro repetições. Os tratamentos consistiram da combinação de oito cultivares (Amélia, Kodama, Luiza, Maria, Marina, Mikado, Triofin e Viçosa), localizadas nas parcelas principais, com as lâminas de água de aproximadamente 156, 177, 239, 311, 395 e $479 \mathrm{~mm}$, localizadas nas subparcelas. A área total de 
cada subparcela foi de $24 \mathrm{~m}^{2}$ ( $\left.6 \times 4 \mathrm{~m}\right)$; a área útil colhida foi de $12 \mathrm{~m}^{2}(4 \times 3 \mathrm{~m})$.

O plantio das cultivares foi realizado na segunda semana de maio de 1995, com espaçamento de $25 \mathrm{~cm}$ entre linhas, semeando-se 30 sementes por metro linear. Os tratos culturais utilizados foram os recomendados para a cultura (Giordano et al., 1997). A área experimental, de $25 \times 150 \mathrm{~m}$, foi naturalmente infestada por Meloidogyne incognita raça 1. Dentre as cultivares, Amélia e Kodama são semi-áfilas. As cultivares apresentaram ciclo vegetativo entre 100 e 120 dias.

Os níveis de irrigação foram obtidos utilizando-se o esquema experimental de aspersão em linha, conforme método proposto por Hanks et al. (1976). Os aspersores, com raio molhado médio de $13 \mathrm{~m}$, foram dispostos com espaçamento de $6,0 \mathrm{~m}$ entre si. Nas lâminas totais de água aplicadas estão incluídos $50 \mathrm{~mm}$ aplicados durante os primeiros 15 dias em todos os tratamentos para garantir a germinação e estabelecimento homogêneo de plantas e $106 \mathrm{~mm}$ de precipitação ocorrida ao longo do ciclo de desenvolvimento da cultura.

A freqüência de irrigação foi determinada com base na leitura de tensiômetros instalados no centro das subparcelas mais próximas à linha de aspersores, na profundidade de $10 \mathrm{~cm}$ até o florescimento e de $20 \mathrm{~cm}$ após o florescimento. A faixa de tensão considerada como limite para reposição de água ao solo foi entre 25 e $35 \mathrm{kPa}$, como forma de garantir, segundo Marouelli et al. (1991), irrigações em excesso para a cultura. A lâmina aplicada por irrigação nas subparcelas mais próximas à linha de aspersores, medida por meio de pluviômetros, foi a necessária para que a umidade do solo, na profundidade efetiva do sistema radicular da cultura, retornasse à capacidade de campo. Nas demais subparcelas, a lâmina de irrigação sofreu redução linear e nas mais afastadas da linha de aspersores, a lâmina foi nula após 15 dias da semeadura.

Foram avaliados o fator de reprodução (FR) e o índice de galhas (IG) de $M$. incognita raça 1 e a produtividade de grãos das cultivares de ervilha. O FR do nematóide em cada cultivar e lâmina de água foi determinado pela razão entre a população final $(\mathrm{Pf})$ e a população inicial $(\mathrm{Pi})$ do nematóide por subparcela. A Pi foi estimada em amostras de $200 \mathrm{~mL}$ de solo, por subparcela, obtidas da homogeneização do solo coletado a $20 \mathrm{~cm}$ de profundidade em cinco pontos distintos, um dia antes do semeio das cultivares. A Pf foi obtida em amostras de $200 \mathrm{~mL}$ do solo da rizosfera, aderido nas raízes de dez plantas de cada cultivar, coletadas ao acaso por subparcela durante a colheita. A extração do nematóide das amostras de solo para determinação das Pi e Pf foi realizada por combinação dos métodos de flutuação, sedimentação, peneiramento e centrifugação em solução de açúcar (Charchar, 2001), para a contagem do número de juvenis de segundo estádio por amostra.

As dez plantas coletadas por subparcela, após a coleta do solo, foram cortadas na região do colo. As raízes foram lavadas em água corrente e enroladas em papel toalha por 20 minutos, para eliminar o excesso de umidade. As galhas causadas pelo nematóide foram contadas em todo sistema radicular de cada planta, sob lupa de vidro com aumento de dez vezes, para determinação do índice de galhas, com o uso de escala cujos valores corresponderam a: 1) raiz sem galhas; 2) raiz com até 10 galhas pequenas; 3 ) raiz com até 50 galhas pequenas; 4) raiz com mais de 50 galhas pequenas e até 10 galhas grandes; 5) raiz com mais de 50 galhas pequenas e mais de 10 galhas grandes. As galhas com diâmetro superior a $3 \mathrm{~mm}$ foram consideradas grandes (Charchar et al., 2003). Os índices de galhas em raízes de ervilha foram determinados por média de dez plantas por cultivar, coletadas por subparcela.

A produtividade de grãos das oito cultivares de ervilha foi estimada em toneladas de grãos secos por hectare.

As análises de variância, de regressão e de comparação de médias foram feitas por meio do Sistema de Análise Estatística (SAS Institute, 1988).

\section{Resultados e Discussão}

A análise de variância do experimento em fatorial, utilizando-se oito cultivares de ervilha (C) e seis lâminas de água (L) em campo de cerrado no Distrito Federal, revelou quanto ao IG que não houve distinção entre cultivares ou entre as lâminas de água e que nem a interação CxL apresentou significância. Quanto ao FR, houve distinção apenas entre as lâminas avaliadas. Entretanto, na produtividade de grãos, houve distinção entre cultivares, entre lâminas e a interação $\mathrm{CxL}$ foi significativa (Tabela 1).

As médias de FR e de IG por cultivar nas seis lâminas de água não diferiram entre si, mostrando que as cultivares apresentaram o mesmo grau de suscetibilidade ao nematóide (Tabela 2). Rossi et al. (2000) demonstraram que as cultivares Maria, Marina e Viçosa foram moderadamente suscetíveis e 'Luiza' suscetível a 
Meloidogyne incognita raça 3 em condições de casa de vegetação. Neste trabalho, essas cultivares apresentaram o mesmo grau de suscetibilidade a $M$. incognita raça 1 em condições de campo. É provável que a pressão de inóculo do nematóide, associada à alta temperatura nas condições de casa de vegetação, tenha influenciado a reação das cultivares.

Houve redução do FR das oito cultivares por lâmina de água em até $60 \%$ nas lâminas de água de 156 e 177 mm, em relação às demais lâminas $(239,311,395$ e $479 \mathrm{~mm}$ ), indicando que o nematóide não tolerou a deficiência hídrica do solo (Tabela 2).

A redução drástica do FR nas cultivares com lâminas de água de 156 e 177 mm não implicou redução do IG

Tabela 1. Valores do teste F da ANOVA e respectivas probabilidades (Prob.) do efeito de diferentes lâminas (L) de água no fator de reprodução e no índice de galhas de Meloidogyne incognita raça 1 e na produtividade de grãos de cultivares (C) de ervilha (Pisum sativum L.).

\begin{tabular}{|c|c|c|c|c|c|c|c|}
\hline \multirow[t]{2}{*}{ Características } & \multicolumn{2}{|c|}{$\mathrm{C}$} & \multicolumn{2}{|c|}{$\mathrm{L}$} & \multicolumn{2}{|c|}{$\mathrm{CxL}$} & \multirow{2}{*}{$\begin{array}{l}\mathrm{CV} \\
(\%)\end{array}$} \\
\hline & $\mathrm{F}$ & Prob. & F & Prob. & $\mathrm{F}$ & Prob. & \\
\hline Fator de reprodução (Pf/Pi) & 1,40 & 0,21 & 5,64 & $<0,01$ & 1,04 & 0,42 & 28,54 \\
\hline Índice de galhas (notas de 1 a 5 ) & 0,61 & - & 1,89 & 0,10 & 0,78 & - & 18,35 \\
\hline Produtividade de grãos $\left(\mathrm{t} \mathrm{ha}^{-1}\right)$ & 25,67 & $<0,01$ & 28,14 & $<0,01$ & 1,61 & 0,03 & 21,99 \\
\hline
\end{tabular}

do nematóide nas cultivares, sugerindo que o nematóide pode ter infectado as cultivares, concluído o processo de formação de galhas nas raízes, sem que ocorresse produção abundante de ovos nas massas gelatinosas, em conseqüência do déficit hídrico. A deficiência hídrica pode ter interferido significativamente também na eclosão de ovos do nematóide, impedindo a liberação de juvenis do segundo estádio para o solo, diminuindo a população do nematóide. A comparação de médias mostrou que não houve diferença significativa de IG do nematóide entre cultivares nas seis diferentes lâminas de água avaliadas (Tabela 2).

As médias de produtividade mostraram que as cultivares não diferiram estatisticamente sob lâminas de água de 395,311 e $239 \mathrm{~mm}$, mas houve redução em 12\%, $30 \%$ e $40 \%$, respectivamente, sob lâminas de 479,177 e $156 \mathrm{~mm}$ no solo, embora a produtividade alcançada sob lâmina de $479 \mathrm{~mm}$ não tenha se diferenciado das produtividades das cultivares sob lâminas de $311 \mathrm{e}$ $239 \mathrm{~mm}$. Esse fato indica que as cultivares de ervilha não toleraram alta e baixa umidade do solo, concordando com os relatos de Marouelli et al. (1991).

Tabela 2. Fator de reprodução e índice de galhas de Meloidogyne incognita raça 1 e produtividade de grãos de oito cultivares de ervilha (Pisum sativum), sob diferentes lâminas de água ${ }^{(1)}$.

\begin{tabular}{|c|c|c|c|c|c|c|c|}
\hline \multirow[t]{2}{*}{ Cultivares } & \multicolumn{6}{|c|}{ Lâminas de água $(\mathrm{mm})$} & \multirow[t]{2}{*}{ Média } \\
\hline & 156 & 177 & 239 & 311 & 395 & 479 & \\
\hline & \multicolumn{7}{|c|}{ Fator de reprodução de $M$. incognita raça 1} \\
\hline Triofin & 3,4 & 2,4 & 25,1 & 25,9 & 19,5 & 26,8 & $17,2 \mathrm{a}$ \\
\hline Mikado & 51,1 & 4,5 & 23,8 & 16,6 & 18,5 & 48,9 & $27,2 \mathrm{a}$ \\
\hline Marina & 10,0 & 8,1 & 16,0 & 20,2 & 30,3 & 26,1 & $18,4 \mathrm{a}$ \\
\hline Viçosa & 11,6 & 51,0 & 99,9 & 36,4 & 37,3 & 14,2 & $41,7 \mathrm{a}$ \\
\hline Maria & 1,5 & 14,9 & 41,2 & 8,1 & 57,6 & 43,5 & $27,8 \mathrm{a}$ \\
\hline Luiza & 33,8 & 24,7 & 12,4 & 52,4 & 16,4 & 20,8 & $26,7 \mathrm{a}$ \\
\hline Amélia & 0,2 & 1,7 & 38,8 & 40,9 & 32,9 & 30,5 & $24,1 \mathrm{a}$ \\
\hline \multirow[t]{2}{*}{ Média } & $14,3 \mathrm{C}$ & $14,8 \mathrm{BC}$ & $35,5 \mathrm{~A}$ & $27,6 \mathrm{AB}$ & $31,2 \mathrm{~A}$ & $29,7 \mathrm{AB}$ & 25,5 \\
\hline & \multicolumn{7}{|c|}{ Índice de galhas de $M$. incognita raça 1} \\
\hline Triofin & 3,3 & 4,0 & 4,3 & 4,0 & 3,9 & 3,1 & $3,8 \mathrm{a}$ \\
\hline Mikado & 4,7 & 4,2 & 3,7 & 3,5 & 4,2 & 4,3 & $4,1 \mathrm{a}$ \\
\hline Marina & 3,7 & 2,7 & 4,1 & 4,0 & 3,8 & 3,5 & $3,6 \mathrm{a}$ \\
\hline Viçosa & 3,8 & 3,7 & 3,8 & 4,4 & 4,0 & 3,6 & $3,9 \mathrm{a}$ \\
\hline Maria & 3,6 & 2,7 & 3,8 & 4,2 & 5,0 & 3,8 & $3,8 \mathrm{a}$ \\
\hline Luiza & 3,6 & 4,0 & 4,3 & 4,2 & 3,3 & 2,8 & $3,7 \mathrm{a}$ \\
\hline Amélia & 4,2 & 3,3 & 4,9 & 4,2 & 4,1 & 3,4 & $4,0 \mathrm{a}$ \\
\hline Média & \multicolumn{7}{|c|}{ Produtividade de grãos $\left(\mathrm{t} \mathrm{ha}^{-1}\right)$} \\
\hline Triofin & $1,33 \mathrm{ab}$ & $1,42 \mathrm{~b}$ & $1,64 \mathrm{ab}$ & $1,57 \mathrm{ab}$ & $1,36 \mathrm{a}$ & $1,23 \mathrm{a}$ & $1,42 \mathrm{bc}$ \\
\hline Mikado & $1,81 \mathrm{a}$ & $2,21 \mathrm{a}$ & $1,76 \mathrm{ab}$ & $1,56 \mathrm{ab}$ & $1,17 \mathrm{a}$ & $0,89 \mathrm{a}$ & $1,57 \mathrm{bcc}$ \\
\hline Marina & $1,57 \mathrm{ab}$ & $1,80 \mathrm{ab}$ & $1,76 \mathrm{ab}$ & $1,82 \mathrm{a}$ & $1,58 \mathrm{a}$ & $1,44 \mathrm{a}$ & $1,66 a b c$ \\
\hline Viçosa & $1,53 \mathrm{ab}$ & $1,64 \mathrm{ab}$ & $1,34 \mathrm{ab}$ & $1,42 \mathrm{ab}$ & $1,01 \mathrm{a}$ & $1,01 \mathrm{a}$ & $1,32 \mathrm{~d}$ \\
\hline Maria & $2,07 \mathrm{a}$ & $2,23 \mathrm{a}$ & $2,09 \mathrm{a}$ & $2,06 a$ & $1,57 \mathrm{a}$ & $1,39 \mathrm{a}$ & $1,90 \mathrm{a}$ \\
\hline Luiza & $1,91 \mathrm{a}$ & $2,01 \mathrm{ab}$ & $1,73 \mathrm{ab}$ & $1,99 \mathrm{a}$ & $1,41 \mathrm{a}$ & $1,22 \mathrm{a}$ & $1,71 \mathrm{ab}$ \\
\hline Amélia & $1,39 \mathrm{ab}$ & $1,79 \mathrm{ab}$ & $1,66 \mathrm{ab}$ & $1,49 \mathrm{ab}$ & $1,04 \mathrm{a}$ & $0,76 \mathrm{a}$ & $1,35 \mathrm{~d}$ \\
\hline Kodama & $0,95 \mathrm{~b}$ & $1,22 \mathrm{~b}$ & $1,02 \mathrm{~b}$ & $0,89 \mathrm{~b}$ & $0,86 \mathrm{a}$ & $0,95 \mathrm{a}$ & $0,98 \mathrm{e}$ \\
\hline Média & $1,11 \mathrm{C}$ & $1,25 \mathrm{C}$ & $1,60 \mathrm{AB}$ & $1,62 \mathrm{AB}$ & $1,79 \mathrm{~A}$ & $1,57 \mathrm{~B}$ & 1,49 \\
\hline
\end{tabular}

${ }^{(1)}$ Médias seguidas da mesma letra, maiúscula na linha e minúscula na coluna, não diferem entre si pelo teste de Tukey a $5 \%$ de probabilidade. 
A análise de variância da regressão das médias mostrou que as lâminas de água tiveram efeitos significativos no fator de reprodução do nematóide e na produtividade de grãos das cultivares de ervilha, mas não apresentaram efeitos no índice de galhas (Figura 1). As variáveis FR e a produtividade de grãos apresentaram respostas semelhantes às lâminas de água. A regressão significativa entre essas duas variáveis foi expressa linearmente com coeficiente de determinação de $81 \%$, evidenciando que, provavelmente, as lâminas de água influenciaram o FR do nematóide e este, por sua vez, afetou a produtividade das cultivares de ervilha.

Resultados semelhantes têm sido obtidos por diferentes autores. Aguiar Netto et al. (1995, 1997) demonstraram que o aumento da tensão de água no solo, no intervalo entre 33 e $1.500 \mathrm{kPa}$, provocou o decréscimo da área foliar e da quantidade da matéria seca de raízes, caules e folhas de plantas da ervilha 'Caprice'. Figuerêdo (1999) recomenda a aplicação da lâmina de água de 400 a $500 \mathrm{~mm}$, de forma parcelada, a fim de repor as necessidades hídricas da ervilha de ciclo longo (110 dias), principalmente no período crítico que se estende do florescimento ao enchimento de grãos. Oliveira et al. (2000) demonstraram o aumento significativo do número de escleródios do fungo Sclerotinia sclerotiorum em cultivares de ervilha, com o aumento da lâmina de água de 259 a $499 \mathrm{~mm}$, bem como a redução do número de escleródios nas lâminas de água de 176 e $196 \mathrm{~mm}$. Resultados semelhantes foram obtidos neste trabalho, em que o FR de M. incognita raça 1 foi maior nas cultivares sob irrigação com lâminas de água de 239 a 479 mm, e sob lâminas de água de 156 e 177 mm, o FR da população do nematóide no solo sofreu drástica redução nas cultivares de ervilha.
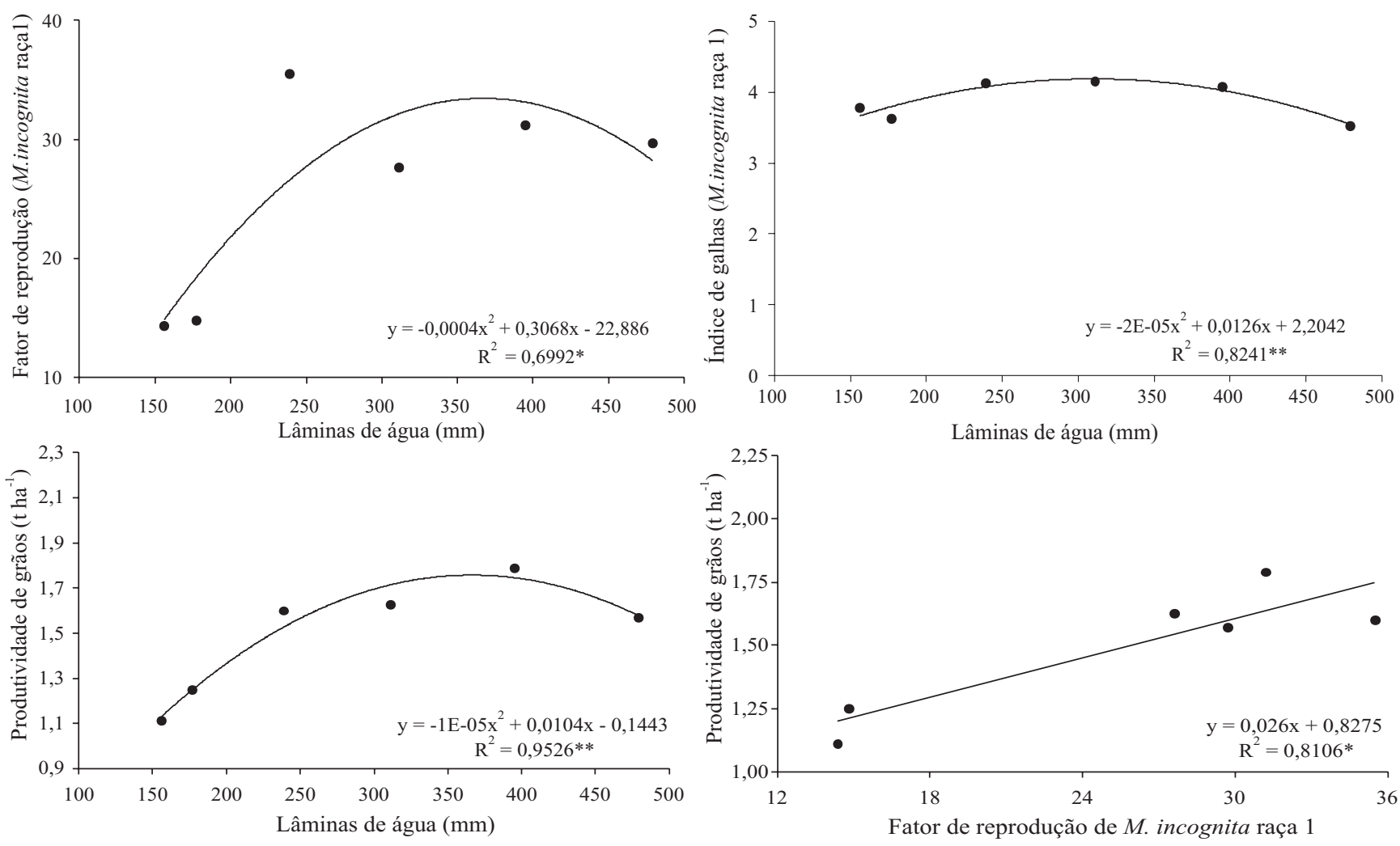

Figura 1. Resposta do fator de reprodução e do índice de galhas de Meloidogyne incognita raça 1 e da produtividade de grãos de ervilhas, em função das diferentes lâminas de água, e regressão linear entre o fator de reprodução do nematóide e a produtividade de grãos de ervilhas. 
As lâminas de água de 395, 311 e 239 mm proporcionaram aumentos de FR do nematóide e de produtividades de grãos, e as lâminas de água de 177 e 156 mm reduziram tanto o FR do nematóide quanto a produtividade de grãos das cultivares de ervilha. Sendo assim, é necessário o estudo de lâminas intermediárias entre 177 e 239 mm, para determinação de uma lâmina de água que favoreça o declínio populacional do nematóide no solo sem redução significativa da produtividade de grãos. Essa lâmina de água poderá ser usada no manejo da irrigação para controle de Meloidogyne spp. no cultivo de ervilha e de outras culturas nos Cerrados do Brasil Central.

\section{Conclusões}

1. O fator de reprodução de $M$. incognita raça 1 apresenta relação quadrática com as lâminas de água, sendo maximizado para $384 \mathrm{~mm}$.

2. O índice de galhas-do-nematóide, nas cultivares avaliadas, mantém-se inalterado nas lâminas de água entre 156 e $479 \mathrm{~mm}$.

3 . As cultivares de ervilha atingem melhores produtividades de grãos sob lâminas de água entre 239 e $395 \mathrm{~mm}$.

4. O fator de reprodução do nematóide e a produtividade de grãos apresentam correlação linear positiva.

\section{Referências}

AGUIAR NETO, A.O.; RODRIGUES, J.D.; BASTOS, E.A.; ONO, E.O. Desenvolvimento de plantas de ervilha (Pisum sativum L.) submetidas a diferentes potenciais da água no solo: índices fisiológicos. Scientia Agricola, v.52, p.521-527, 1995.

AGUiAR NETTO, A.O.; RODRIGUES, J.D.; PINHO, S.Z. Desenvolvimento de plantas de ervilha (Pisum sativum L.), submetidas a diferentes potenciais da água no solo: medidas biométricas. Revista de Agricultura, v.72, p.39-51, 1997.

CHARCHAR, J.M. Meloidogyne em hortaliças. In: CONGRESSO INTERNACIONAL DE NEMATOLOGIA TROPICAL, 19., 1995, Rio Quente. Programa e anais. Brasília: SBN, 1995. p.149-153.

CHARCHAR, J.M. Métodos simplificados em nematologia. Brasília: Embrapa Hortaliças, 2001. 12p. (Embrapa Hortaliças. Circular técnica, 23).
CHARCHAR, J.M. Nematóides em hortaliças. Brasília: EmbrapaCNPH, 1999. 12p. (Embrapa-CNPH. Circular técnica, 18).

CHARCHAR, J.M.; ARAGÃO, F.A.S. Seqüência de cultivos no controle de Meloidogyne javanica em campo. Nematologia Brasileira, v.27, p.81-86, 2003.

CHARCHAR, J.M.; GONZAGA, V.; GIORDANO, L.B.; BOITEUX, L.S.; REIS, N.B.V.; ARAGÃO, F.A.S. Reações de cultivares de tomateiro à infecção por população mista de Meloidogyne incognita raça 1 e $M$. javanica em estufa plástica e campo. Nematologia Brasileira, v.27, p.49-54, 2003.

CAMACHO, R.; CALVACHE, A.M.; FALCÃO, N.; FERNANDEZ, F.; DEMATTE, J.A.M.; MALAVOLTA, E. Avaliação do estado nutricional do feijoeiro (Phaseolus vulgaris L.) cultivado em solução nutritiva, com variação no fornecimento de $\mathrm{N}$, P e K. Scientia Agricola, v.52, p.422-425, 1995.

FAO. FAOSTAT. Disponível em: <http://www.apps.fao.org>. Acesso em: 7 jun. 2004.

FIGUERÊDO, S.F. Manejo de irrigação para a cultura da ervilha. Planaltina: Embrapa-CPAC, 1999. 1p. (Embrapa-CPAC. Guia técnico do produtor rural, 49).

GENUCHTEN, M.T. van. A closed-form equation for predicting the hydraulic conductivity of unsaturated soils. Soil Science Society of American Journal, v.50, p.288-291, 1980.

GIORDANO, L.B.; LOPES, C.A.; FRANÇA, F.H.; SILVA, H.R.; PESSOA, H.B.S.V.; SANTOS, J.R.M.; MAROUELLI, W.A.; PEREIRA, W. Cultivo da ervilha (Pisum sativum L.). 3.ed. Brasília: Embrapa-CNPH, 1997. 20p. (Embrapa-CNPH. Instruções técnicas, 3).

HANKS, R.J.; KELLER, J.; RASMUSSEM, V.P.; WILSON, G.A. Line source sprinkler for continuous variable irrigationcrop studies. Soil Science Society of American Journal, v.40, p.426-429, 1976.

MAROUELLI, W.A.; GIORDANO, L.B.; OLIVEIRA, C.A. da S.; CARRIJO, O.A. Desenvolvimento, produção e qualidade de ervilha sob diferentes tensões de água no solo. Pesquisa Agropecuária Brasileira, v.26, p.1041-1047, 1991.

OLIVEIRA, C.A.S.; MAROUELLI, W.A.; SANTOS, J.R.M.; GIORDANO, L.B. Produção de escleródios de Sclerotinia sclerotiorum e severidade de oídio em cultivares de ervilha sob diferentes lâminas de água. Horticultura Brasileira, v.18, p.16-20, 2000.

PENÃ, R.P. A nutrição das plantas e seus efeitos na sanidade vegetal. Agricultura Biodinâmica, v.17, p.26-30, 2000.

ROSSI, C.E.; ARAÚJO, A.C.M.; FERRAZ, L.C.C.B. Preliminary evaluation of Meloidogyne incognita race 3 reproduction on garden cultivars in Brazil. Semina: Ciências Agrárias, v.21, p.97-99, 2000.

SANTOS, J.R.M. Doenças da ervilha. In: ZAMBOLIM, L.; VALE, F.X.R.; COSTA, H. (Ed.). Controle de doenças de plantas: hortaliças. Viçosa: UFV, 2000. v.1, p.409-440.

SANTOS, M.A.; FERRAZ, S. Doenças causadas por nematóides em hortaliças leguminosas. Informe Agropecuário, v.17, p.74-75, 1995. 
SAS Institute (Cary, Estados Unidos). SAS/STAT user's guide; release 6.03. Cary, 1988.

SHARMA, R.D.; FONSECA, C.E.L. Efeito de Meloidogyne javanica no crescimento da ervilha. Pesquisa Agropecuária Brasileira, v.35, p.115-120, 2000.

SIDDIQUI, Z.A.; MAHMOOD, I.; ANSARI, M.A. Effect of different inoculum levels of Meloidogyne incognita on the growth of pea in the presence and absence of Rhizobium. Nematologia Mediterranea, v.23, p.249-251, 1995.

SOUZA, J.T.; CAMPOS, V.P.; MAXIMINIANO, C. Ocorrência e distribuição de nematóides associados a hortaliças e plantas medicinais. Summa Phytopathologica, v.24, p.283-290, 1998.

ZAMBOLIM, L.; VALE, F.X.R.; COSTA, H. Controle integrado das doenças de hortaliças. Viçosa: UFV, 1997. 123p.

Recebido em 23 de abril de 2004 e aprovado em 2 de abril de 2005 